\title{
Orbitally forced groundwater circulation and sphalerite growth in the Upper Mississippi Valley District
}

\begin{abstract}
MingSONG Li ${ }^{1}$, HubERT L. BARNES ${ }^{1}$
${ }^{1}$ Department of Geosciences, Pennsylvania State University, University Park, PA 16802, USA; mul450@psu.edu

Groundwater plays an essential role in global water cycles via feedback between groundwater and climate systems. However, the geologic history of groundwater activity remains unclear due to limited data. Sphalerite color banding in the Upper Mississippi Valley District (USA) is apparently caused by variation in oxidation state during sulfide precipitation which is controlled by the penetration of deeply circulating groundwater. Here, time series analysis of the grayscale profile of the Permian sphalerite banding in this district shows the banding correlates with Earth's eccentricity, obliquity, and precession forcing.

We have found that this astronomical forcing controlled penetration of groundwater into sedimentary hydrothermal fluids which regulated regionally the penetration of groundwater into the ore zone to fixt sphalerite banding. Orbital forcing of climate had a significant impact on a groundwater reservoir at depths near $1 \mathrm{~km}$. The results demonstrate that banding in sphalerite follows the Milankovitch climate frequencies over $10^{3}-10^{5}$ years. Consequently, groundwater oxidation has a major role in depositing the iron-rich bands of the sphalerite and, as a final corollary, that the banding itself can be used to decipher the effects of climate on groundwater variations in the global water cycle.
\end{abstract}

Table 1. Sphalerite iron banding and orbital periodicities.

\begin{tabular}{c|c|c|c}
\hline \multirow{2}{*}{$\begin{array}{c}\text { Wavelengths } \\
\text { of bands } \\
(\mathrm{mm})\end{array}$} & \multicolumn{2}{|c|}{ Orbital cycles (kyr) } & \multirow{2}{*}{$\begin{array}{c}\text { Orbital } \\
\text { elements }\end{array}$} \\
\cline { 2 - 3 } & Permian & Today & \\
\hline 32 & $\sim 100$ & $\sim 100$ & Eccentricity \\
8.8 & 35 & 41 & Obliquity \\
$\sim 3.8,3.1$ & 21,18 & 24,19 & Precession \\
\hline
\end{tabular}

